\title{
Intraday volume-volatility nexus in the FX markets: Evidence from an emerging market ${ }^{\text {th }}$
}

\author{
Ahmet Sensoy $^{\mathrm{a}, *}$, Süleyman Serdengeçti ${ }^{\mathrm{a}} \mathrm{b}$ \\ ${ }^{a}$ Bilkent University, Faculty of Business Administration, 06800, Cankaya, Ankara, Turkey \\ ${ }^{\mathrm{b}}$ Central Bank of the Republic of Turkey, Research and Monetary Policy Department, 06050, Ulus, Ankara, Turkey
}

\section{A R T I C L E I N F O}

\section{Keywords:}

FX microstructure

Volume-volatility nexus

Mixture of distribution hypothesis (MDH)

Sequential information arrival hypothesis (SIAH)

Dispersion of beliefs hypothesis (DBH)

\begin{abstract}
A B S T R A C T
Using a dataset on local banks' daily FX transaction volume segregated into counterparty and transaction types, this article investigates the relationship between trading volume and intraday realized volatility for the US dollar/Turkish lira parity (USDTRY), one of the most traded emerging market currencies against US dollar. We question whether type of counterparty and transaction affects intraday volume-volatility relationship across various trading sessions around the world. We reveal that only the spot transactions of domestic customers have positive contemporaneous relation with realized volatility and this significance is valid only in global trading sessions that mostly overlap with the local trading hours. Furthermore, we utilize a metric for the belief dispersion on the level of future exchange rate via currency options and find that the dispersion significantly strengthens the volume-volatility nexus, confirming the Dispersion of Beliefs Hypothesis.
\end{abstract}

\section{Introduction}

The volume-volatility relationship has long been an interest for microstructure research as it has implications for trading, risk management and policy making objectives. Long before the availability of financial market data, there were several papers trying to set up a theoretical background for the relationship between these two variables. In the competitive models such as the ones by Easley and O'Hara (1987) and Holthausen and Verrecchia (1990), the expected outcome would be a positive relationship between volume and volatility due to the price impact by informed traders who submit large orders. However, in the strategic models by Foster and Viswanathan (1996), Kyle (1985) and Chordia and Subrahmanyam (2004), informed traders submit splitted orders in order to hide their private information, yielding to small executed trades hence a weak or even a negative relationship between volume and volatility.

The competitive theoretical models in the abovementioned papers indeed depend on two famous hypothesis, namely mixture of distribution hypothesis (MDH) of Clark (1973) and sequential information arrival hypothesis (SIAH) of Copeland (1976). While stochastic arrival of information and positive relationship between volume and volatility are proposed by both hypotheses, their approach on how the equilibrium is restored differs. MDH implies a contemporaneous relationship between volume and volatility as both variables are driven by the same mixing variable, the flow of information. ${ }^{1}$ In SIAH, agents receive information sequentially and the equilibrium is established only when the information is disseminated to all agents and they have identical set of information. Numerous studies empirically tested these two hypotheses and found that the validity of these hypotheses are market and state dependent. For instance, (Foster, 1995) investigates oil futures market and finds supporting evidence for $\mathrm{MDH}$ as volume and volatility is contemporaneously determined in this market. Likewise, Ciner (2002) and Luu and Martens (2003) confirm the MDH for S\&P500 Index futures contracts and commodity futures markets respectively. In the case of currency futures, Bauwens, Omrane, and Giot (2005) find a positive relationship between volume and volatility for the intraday Euro/USD parity from May 2001 to November 2001, again supporting the MDH. On the other hand, Mougoué and Aggarwal (2011) reject the validity of MDH but accepts SIAH for GBP, JPY and CAD currency futures. Being among a few studies focusing on spot foreign exchange markets, Galati (2001) investigates volume-volatility relation for seven emerging market currencies including the Indonesian rupiah, the Indian rupee,

\footnotetext{
the views expressed in this work are those of the authors and should not be attributed to the Central Bank of the Republic of Turkey. This paper is a part of Suleyman Serdengecti's Ph.D. study in the Faculty of Business Administration in I.D. Bilkent University.

* Corresponding author.

E-mail address: ahmet.sensoy@bilkent.edu.tr (A. Sensoy).

${ }^{1} \mathrm{Li}$ and Wu (2006) examine the volume-volatility relationship with the control for information flow. Accordingly, authors are able to provide a theoretical support for a negative relationship between volume and volatility based on the MDH framework.
} 
the Mexican peso, the Brazilian real, the Colombian peso, the South African rand and the Israeli shekel. Except for the Mexican peso and the Brazilian real, author finds positive and contemporaneous relationship between trading volume and volatility supporting the MDH. In addition to that, results by Bjønnes, Rime, and Solheim (2005a) for the daily Swedish Krona/Euro exchange rate between 1995 and 2002, and Bauwens, Rime, and Sucarrat (2006) for the weekly Norwegian Krone/ Euro exchange rate over January 1993 to December 2003 also support the MDH.

A recent hypothesis regarding the volume-volatility nexus belongs to Harris and Raviv (1993) and Shalen (1993). According to their dispersion of beliefs hypothesis (DBH) that builds upon $\mathrm{MDH}$, an asymmetric relationship between volume and volatility is possible due to the heterogeneous interpretation of the same publicly available information by market participants. This hypothesis is empirically supported by the works of Balduzzi, Kallal, and Longin (1996), Chen (2012), Giot, Laurent, and Petitjean (2010), Wagner and Marsh (2005) and Koubaa and Slim (2019), in which volume-volatility relationship is found to have various asymmetric structures through the evolution of financial markets across different periods of the business cycles.

Although there is a vast amount of studies in the literature on the volume-volatility relationship in the stock markets, the same literature for the FX market remains limited due to its fragmented structure, hence lack of reliable trade volume data. In addition to that, the size and structure of FX market and the variety of traders in the market necessitate elaboration of volume-volatility relation in consideration of trader types, transaction types and trading sessions for several reasons. First of all, although they acquire the same information, interpretation and acting on this information may differ among traders as suggested by the DBH. Daigler and Wiley (1999) argue that the type of trader matters for volume-volatility relationship and show that the positive relationship between the two variables is determined by general public. They propose that the uninformed traders, who are mostly the general public, cannot differentiate between the volume arising from liquidity demand and the volume due to a change in fundamental value and thus their trading activity increases volatility. Second, unlike the case of stock markets, timing of traders' presence in the market may differ due to different trading sessions. Many studies show that the intraday volatility and volume patterns mostly overlap. In the model of Admati and Pfleiderer (1988), the reason why trading volume and volatility is concentrated in certain periods is explained by strategic behaviour of liquidity traders and informed traders. Daigler and Wiley (1999) suggest that intraday volatilities can be more related with daily volume as majority of the transactions are made in normal trading hours. However, critical news arrival may create volatility out of local trading hours as well. For instance, as stated by Fischer and Ranaldo (2008), global FX trading volume increases around FOMC announcements but the volume and volatility relationship is expected to be stronger for transactions of foreign investors compared to local investors since local trading session is closed around announcements. Third, there is significant variation in liquidity in different trading sessions which may affect volume-volatility relation across different trading sessions. Osler (2008) states that except from USD, EUR and JPY, the liquidity in most of the currencies are concentrated around local trading hours. For example, a lower volume may trigger higher volatility in a low liquidity environment. Thus, the volatility and volume relation in non-trading hours may be weaker. Fourth, as size of the market participants increase, their trade size and information quality increases as well. Chan and Fong (2000) find that trade size is more important than number of trades for volume-volatility relationship. Large currency orders are more likely to be placed by informed traders (Easley \& O'Hara, 1987) and larger trades are associated with higher volatility (Gradojevic, Erdemlioglu, \& Gençay, 2017). Chang, Michael Pinegar, and Schachter (1997) find that volume-volatility relationship is much stronger for trades of large speculators in commodity and bond market futures. Supporting these views, Bjønnes, Rime, and Solheim (2005b) provide evidence for differentiation of volume-volatility relationship across participants such that trading volume by large banks increases volatility the most and they also document that large players have relation with the determinants of timing of speculative attacks (Bjønnes, Holden, Rime, \& Solheim, 2014). Fifth, it is crucial to discriminate across contract types as their cash flows and intention of use may differ. For example, at the initial agreement of forward contracts there is no initial cash flows. ${ }^{2}$ On the other hand, there is simultaneous buying and selling of local currency and foreign currency for FX swaps. The impact on the liquidity is determined by the sides and currency legs of these contracts. In addition, the use of FX swaps and forwards for either speculative or hedging purposes may have different impact on the relationship between trading volume and realized volatility. For instance, while forwards are used for speculative positioning, use of FX swaps are more common for hedging the currency exposure. This argument is supported by Gargano, Riddiough, and Sarno (2008) who show that information content of volume depends on the traded instrument.

As stated above, the literature on volume-volatility relationship in FX markets is scarce and to the best of our knowledge, the only studies among those that focus on the impact of participant and contract type belong to Bjønnes et al. (2005a) and Bjønnes et al. (2005b). The reason is the fact that unlike financial assets that are traded in organized exchanges, foreign exchange transactions occur mostly in the over-thecounter markets in which information on trades are not kept under a central database. In this study, we contribute to this sparse literature in at least two main ways by utilizing a dataset of the Central Bank of the Republic of Turkey that covers all daily foreign currency transactions traded against Turkish Lira (TRY) by local banks segregated at the trader type and instrument type level. First, we investigate the volumevolatility relationship in the FX market controlling for time of the day, participant type and instrument type concurrently for the first time in the literature. This analysis adds insights on how banks' trading activity with a particular type of counterparty and contract affects intra-daily volatility in each trading session. Second, our results provide intuition on the source and timing of exchange rate volatility that yields to implications for a more precise policy making and investment strategies.

Accordingly, we find significant positive contemporaneous relationship between volume and volatility only for spot and forward transactions of domestic customers. This finding partially supports the MDH in the FX markets and is consistent with the literature proposing that it is the uninformed and retail traders that create volatility. Further, the regression results for realized volatilities of different trading sessions suggest that the positive or negative relationship between volume and volatility is stronger in times when the majority of transactions occur such as the local and London trading sessions (which overlaps the most with the local trading session). Our dynamic model, on the other hand, shows that there is no bivariate Granger causality between any of the realized volatility and transaction volume combination, rejecting the SIAH. Furthermore, we document that the correlation between spot trading volume of both foreign and domestic customers and realized volatility is time varying, and higher contemporaneous correlation between volume and volatility is associated with the higher dispersion of beliefs on the future USDTRY exchange rate level. Our results not only re-iterate previous findings that the relationship depends on the counterparty and transaction type but also provide new evidence on the impact of the investigated trading session. In addition, consistent with the late studies, we show that level and dispersion of beliefs on the future level of exchange rate reinforces contemporaneous correlation between the two variables.

The rest of the paper is organized as the following: In Section 2, we begin by describing the data and provide summary statistics. Section 3

\footnotetext{
${ }^{2}$ Forwards do not incur initial cash flow but they can be part of a multiple transaction strategy. For instance, a foreign investor might simultaneously buy TRY spot and write a put option or sell it forward.
} 
Table 1

Summary statistics for FX transactions of banks against TRY.

\begin{tabular}{|c|c|c|c|c|c|c|c|c|}
\hline Counterparty & Transaction & Min & Max & Mean & Std. & Obs. & ADF Test & PP-Test \\
\hline \multirow[t]{3}{*}{ Domestic interbank } & Spot & 36 & 3270 & 537 & 290 & 1355 & $-5.8 * * *$ & $-973.9^{* * *}$ \\
\hline & Forward & 0 & 359 & 57 & 68 & 1355 & $-3.2^{*}$ & $-247.4^{* * *}$ \\
\hline & Swap & 0 & 922 & 272 & 160 & 1355 & $-5.9 * * *$ & $-932.4 * * *$ \\
\hline \multirow{3}{*}{ Domestic customers } & Spot & 2105 & 14,870 & 4304 & 1019 & 1355 & $-7.9 * * *$ & $-927.7^{* * *}$ \\
\hline & Forward & 94 & 3094 & 631 & 338 & 1355 & $-3.7^{* *}$ & $-499.8^{* * *}$ \\
\hline & Swap & 56 & 1671 & 471 & 230 & 1355 & $-4.6 * * *$ & $-721.8^{* * *}$ \\
\hline \multirow[t]{3}{*}{ Foreign customers } & Spot & 465 & 7225 & 3229 & 895 & 1355 & $-7.6^{* * *}$ & $-875.1^{* * *}$ \\
\hline & Forward & 11 & 2939 & 502 & 359 & 1355 & $-5.7 * * *$ & $-1092.3^{* * *}$ \\
\hline & Swap & 187 & 16,899 & 7428 & 2669 & 1355 & $-5.8 * * *$ & $-742.2^{* * *}$ \\
\hline \multirow[t]{3}{*}{ Total } & Spot & 3504 & 18,769 & 8070 & 1628 & 1355 & $-6.9^{* * *}$ & $-936.5^{* * *}$ \\
\hline & Forward & 181 & 5051 & 1190 & 637 & 1355 & $-4.2^{* * *}$ & $-582.8^{* * *}$ \\
\hline & Swap & 249 & 18,100 & 8171 & 2750 & 1355 & $-6.2^{* * *}$ & $-792.2^{* * *}$ \\
\hline
\end{tabular}

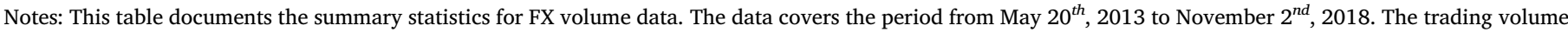

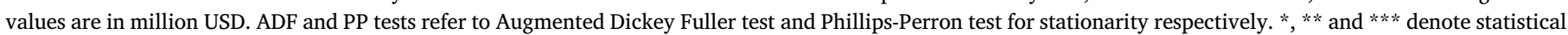
significance at $10 \%, 5 \%$ and $1 \%$ respectively.

first proposes the hypotheses and defines the econometric setting, then discusses empirical results. Finally, Section 4 concludes.

\section{Data and summary statistics}

Our data comes from the Central Bank of the Republic of Turkey (CBRT) and the sample covers the period from May $20^{\text {th }}, 2013$ to November $2^{\text {nd }}, 2018$, consisting of 1355 daily observations after excluding public holidays in Turkey and December $25^{\text {th }}$ where most of the major financial markets are closed. Volume of foreign exchange transactions are reported to CBRT by local banks on a daily basis. The data includes all foreign currency transactions traded against TRY by local banks and compromised of 2 dimensions. In the first dimension, the total transaction volume is disaggregated into 4 type of counterparties: (i) Domestic interbank transactions represent transaction volume among domestic banks including the CBRT. For this category, since two sides of the transaction are banks, transaction amounts are divided by two to avoid double reporting in the analysis; (ii) transactions with domestic customers include domestic retail and institutional customers; (iii) the transactions of banks with their branches and headquarters located outside of Turkey (which are omitted in the analysis since they are more likely to be accounting purposes rather than actual trade); and (iv) transactions with foreign institutional and retail customers are aggregated under foreign customers category. The second dimension disaggregates each type of counterparty transaction volume into 3 types: (i) Spot transactions include purchase or sale of TRY against a foreign currency with value date up to 2 days; (ii) forward transactions include all derivative contracts (except FX swap transactions) such as options, forwards, interest swaps etc.; and (iii) swap transactions consist of FX swap contracts as of value date.

Table 1 gives the summary statistics of transaction volumes data. ${ }^{3}$ Majority of total transactions are made with foreign customers and their total transaction volume is twice the domestic customers. In terms of transaction types, swap and spot transactions constitute big part the total transactions. While domestic customers are more active in spot transactions, $70 \%$ of the transactions with foreign customers are carried out via FX swap contracts. The last two columns provide Augmented Dickey Fuller test and Phillips-Perron test statistics which reveal that the trade volume series under consideration are trend stationary.

\footnotetext{
${ }^{3}$ To give an idea for the coverage of our data, we can compare it with Triennial Central Bank Survey of Foreign Exchange and OTC Derivatives Markets of Bank for International Settlements (BIS, 2016) which gives average daily transaction volumes for April 2016. For spot, forward and swap transactions, daily averages of the same month of our data corresponds $107 \%, 27 \%$ and $61 \%$ of this BIS transaction volume data. Overall, our data represents a big portion of total FX trading volume for USDTRY exchange rate.
}

We obtain high-frequency USDTRY exchange rate data from Bloomberg. TRY ${ }^{4}$ is continuously traded over all trading sessions under consideration. For each trading session, the daily intraday realized volatility proxies are calculated by summing up squares of logarithmic returns for 5-min intervals. Fig. 1 displays the trading hours of major forex markets with respect to local time in Turkey. For each market, trading sessions span between 08:00 and 17:00 in their own local time. ${ }^{5}$ Local trading hours in Turkey have overlapping periods with all other trading sessions and the biggest overlap is with London trading hours. The overlapping periods change with the switches between standard time (ST) and daylight saving time (DST).

In Table 2, summary statistics of 5-min USDTRY log-returns and the corresponding realized volatilities across main forex trading sessions are documented. On average, while highest depreciation occurs in Tokyo session, volatility is higher in the local trading session. This is consistent with theoretical models in which volatility and volume is highest when the arrival of information is more intense. In terms of returns, one can observe that TRY appreciates on the average only in New York session. This is also consistent with the previous literature on intraday patterns that find home currencies are inclined to depreciate during domestic trading sessions and appreciate during off-shore trading sessions (Breedon \& Ranaldo, 2013; Zhang, 2018). Moreover, although mean realized volatility is highest in local trading session, the variation in realized volatility is highest in the NY session.

The hourly patterns in Fig. 2 display the differential impact of counterparty types and transaction types on both USDTRY realized volatility and its unconditional correlations between trading volume. In the top sub-figure of the Fig. 2, we show the impact of differential counterparty transactions. The realized volatility is stronger for local trading hours as majority of the information arrival and thus the transactions occur during these hours. Furthermore, when we condition upon the days of high domestic activity and low foreign customer activity, we observe that on the average the volatility is lower. Differential between the two patterns in top of Fig. 2 also supports the hypothesis that the daily volatility pattern depends on the relative intensity of the counterparty type. For instance, although volatility is consistent with a U-shaped pattern as frequently observed in the literature, a careful reader can identify that the lunch break impact for domestic customers is higher compared to foreign customers, and the time zone differential is evident for the foreign customers as well.

\footnotetext{
${ }^{4}$ Turkish lira is freely convertible and has one of the most liquid and liberal FX markets among emerging market currencies. According to BIS (2016), it has the $16^{\text {th }}$ highest FX turnover currency. In the special case of emerging market currencies, TRY ranks $3^{\text {rd }}$ after Chinese yuan and Mexican peso.

${ }^{5}$ In different sources, the trading hours are shown differently but for consistency we assume 08:00 to 17:00 for all.
} 


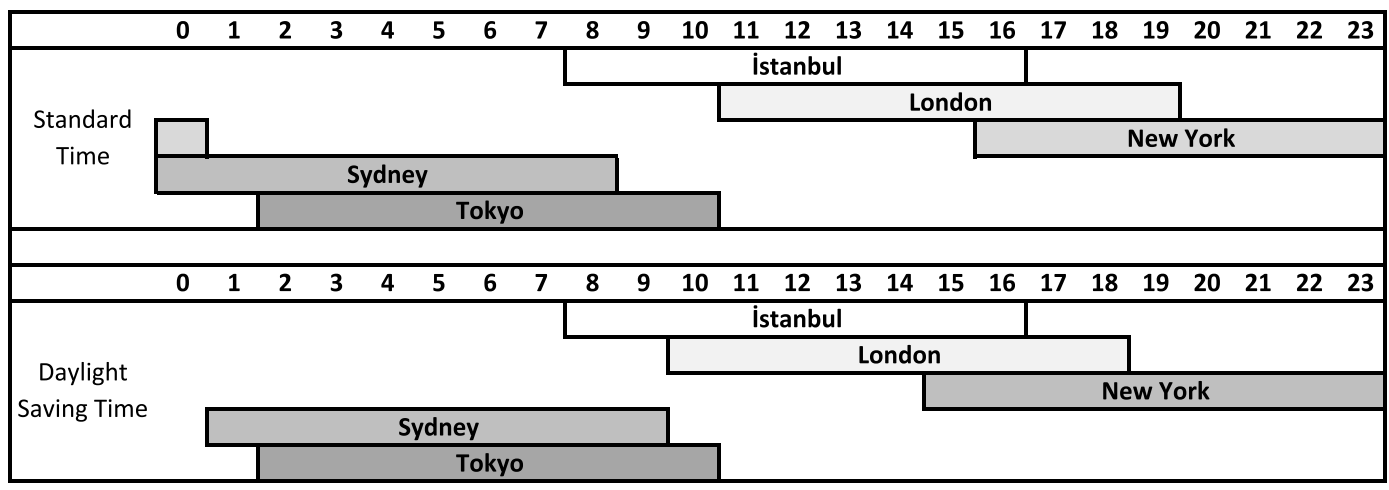

Fig. 1. Hours of FX trading sessions in different locations.

Table 2

Summary statistics for USDTRY returns and volatility across trading sessions.

\begin{tabular}{|c|c|c|c|c|c|c|c|c|c|}
\hline & \multicolumn{4}{|c|}{ Panel A: Log returns } & \multicolumn{4}{|c|}{ Panel B: Realized volatility } & \multirow[t]{2}{*}{ Obs. } \\
\hline & Min & Max & Mean & Std. & Min & Max & Mean & Std. & \\
\hline IST & -2.7479 & 5.3760 & 0.0103 & 0.3325 & 0.0052 & 25.7441 & 0.1292 & 0.8306 & 1355 \\
\hline LDN & -1.5944 & 4.6955 & 0.0048 & 0.3324 & 0.0056 & 21.4501 & 0.1208 & 0.6731 & 1355 \\
\hline NYC & -2.9172 & 6.4646 & -0.0117 & 0.3145 & 0.0025 & 41.0983 & 0.1054 & 1.1307 & 1355 \\
\hline TKY & -3.1550 & 3.3748 & 0.0213 & 0.2289 & 0.0012 & 11.2594 & 0.0604 & 0.4404 & 1355 \\
\hline SYD & -2.5130 & 2.0598 & 0.0167 & 0.1894 & 0.0006 & 11.8344 & 0.0513 & 0.4336 & 1355 \\
\hline
\end{tabular}

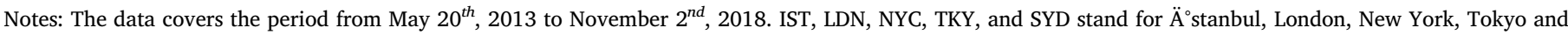

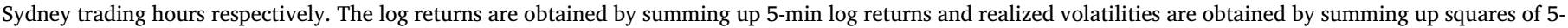
min log returns between 08:00 to 17:00 for each trading session.

Bottom sub-figure of Fig. 2 provides contemporaneous correlations between the volume of two most traded instrument types (spot and swap) and hourly USDTRY realized volatilities. While the spot transactions of domestic customers are positively correlated with the volatility, the correlation between realized volatility and foreign customer swap transactions is negative for all hourly intervals. The correlations of domestic spot transactions and realized volatility show a similar pattern with the intraday volatility as they are higher in local trading sessions and reach the local minimum around lunch hours. On the other hand, negative correlation between swap transactions and realized volatility is stronger around opening and closing hours of the London trading session.

\section{Methodology and results}

As a proxy of volatility we use realized volatility obtained from 5min USDTRY exchange rate data since realized volatility estimates are less noisy than widely used other volatility measures such as absolute returns (Chan \& Fong, 2006), and it allows us to estimate volatility precisely for each trading session. To obtain an intraday volatility measure for each trading session, we first calculate log returns for each 5-min interval as follows:

$r_{t}=\log \left(p_{t}\right)-\log \left(p_{t-1}\right)$

where $p_{t}$ is the USDTRY exchange rate in interval $t$. Realized volatility for trading session $i$ on day $t$ is then obtained with the following equation:

$R V_{t}^{i}=\sum_{j=1}^{T} r_{j}^{2}$

where $T$ is the number of 5-min observations (i.e. 108) in each trading session.

Previous studies emphasize the importance of decomposition of volume data into expected and unexpected components. Bessembinder and Seguin (1993) argue that it is the unexpected component of volume that has strongly positive relationship with volatility. Expected component of the volume has a negative relation with volatility as it enhances liquidity and market depth. As an important component of expected volume, many studies document the day of the week effects for retail and institutional investors (Lakonishok \& Maberly, 1990). The weekly patterns in Fig. 3 indicate that this argument is valid in our dataset as well. The patterns suggest that the day of the week effect differs for domestic and foreign customers in the sense that while domestic customer transactions are higher on Monday and Friday, both spot and swap transactions by foreigners are more concentrated in the middle of a business week.

These observations lead us to apply a decomposition procedure which involves fitting an ARMA model with the day of the week dummies as external regressors, as suggested by Bjønnes et al. (2005b). We estimate an $\operatorname{ARMA}(p, q)$ model where the optimal $p$ and $q$ are determined according to Bayesian Information Criteria (BIC). The resulting residuals from the estimation are used as unexpected volumes.

Vol $_{t}=\sum_{i=1}^{p} \operatorname{Vol}_{t-p}+\epsilon_{t}+\sum_{j=1}^{q} \epsilon_{t-q}+\sum_{k=1}^{4}$ DayDummy $_{k}$

Once we obtain daily series for unexpected transaction volumes and realized volatility for each trading session, we carry out contemporaneous and dynamic analysis for volume-volatility relationship in the rest of this paper.

\subsection{Contemporaneous relations}

Examining the existence of a simultaneous relationship between volume and volatility requires a correct treatment of simultaneity bias as both variables are endogenously determined. Thus, following previous empirical studies in analysing contemporaneous relations, we employ the generalized method of moments (GMM) technique which not only fixes simultaneity bias but also gives heteroskedasticity consistent standard errors in our estimations (Foster, 1995; Mougoué \& Aggarwal, 2011). Using lagged values of endogenous variables as 

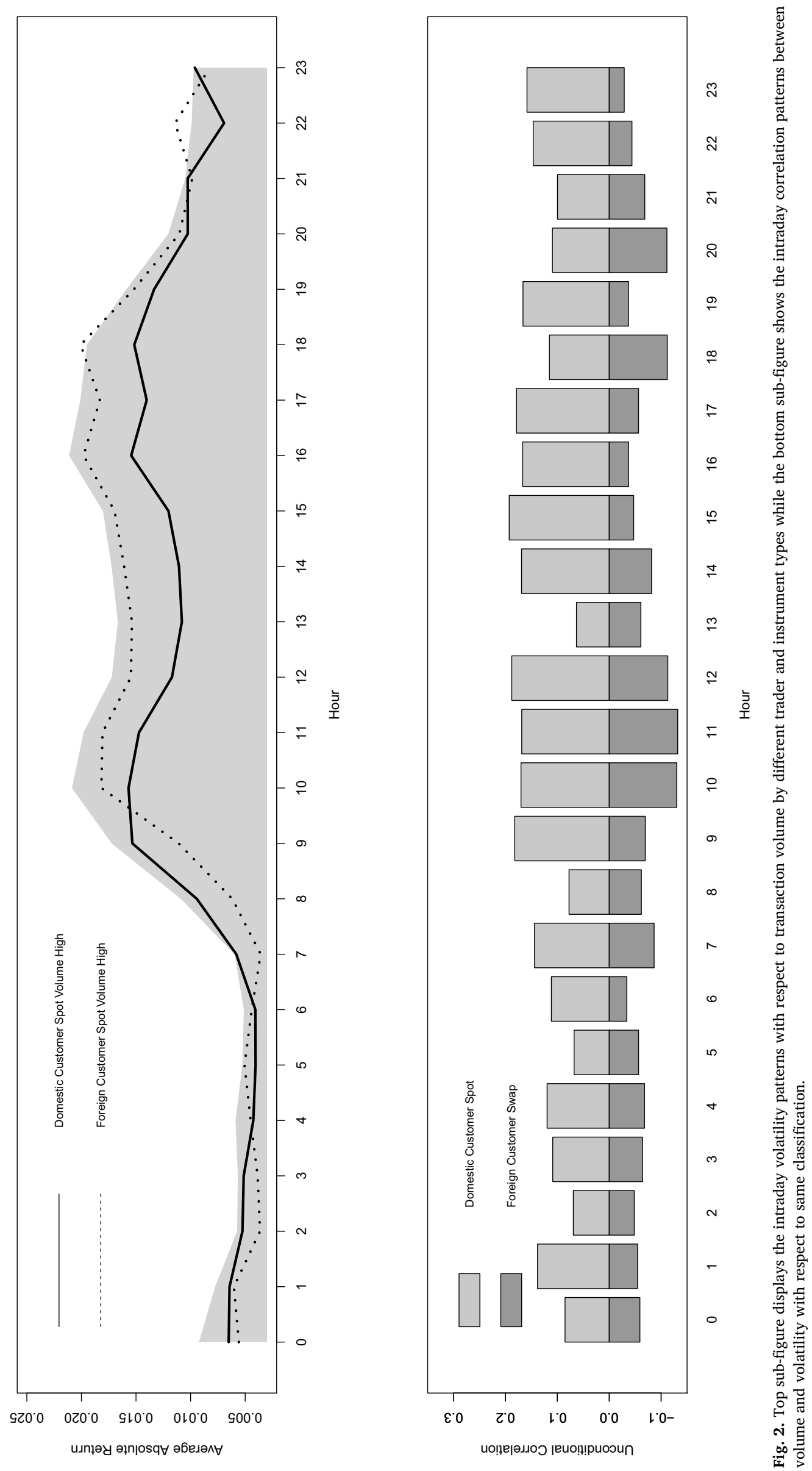

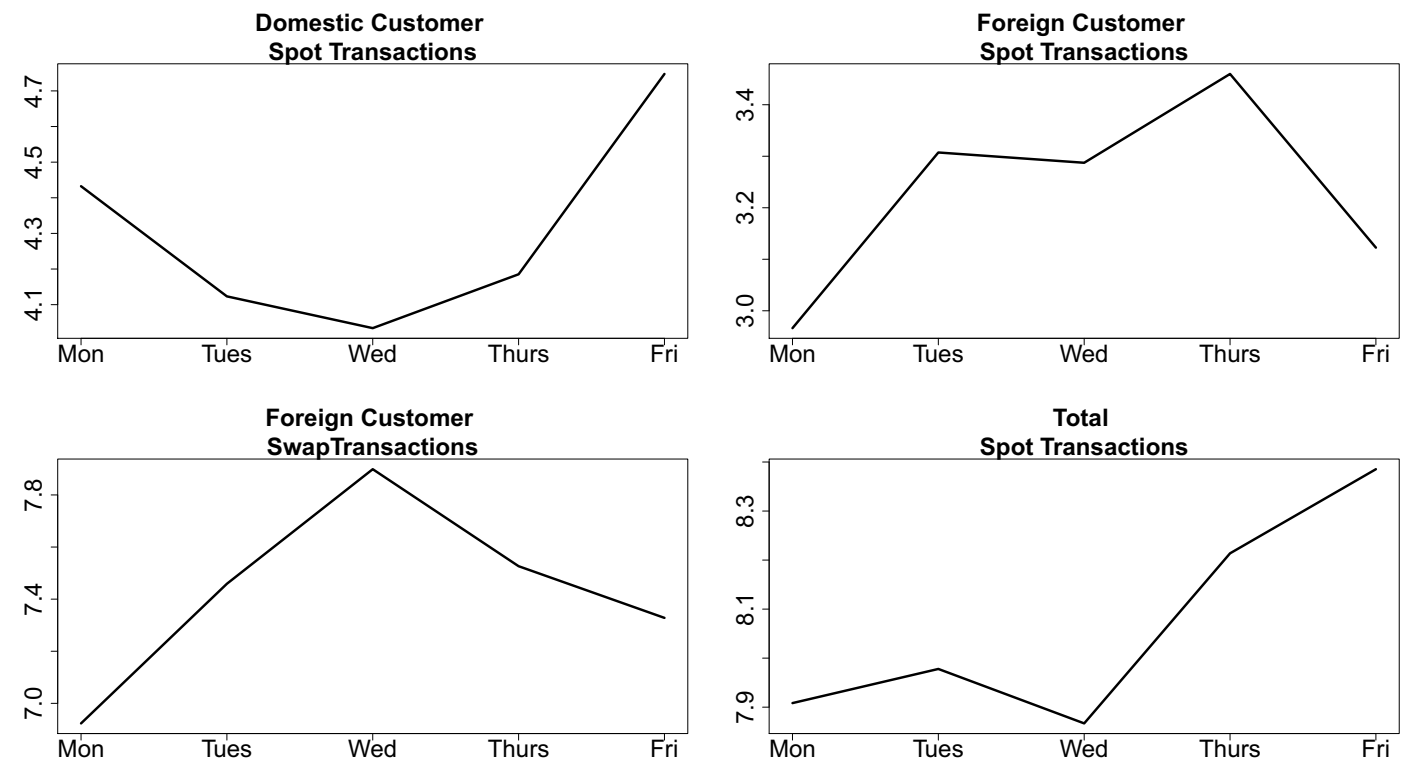

Fig. 3. Average transaction volumes (in USD billions) by the day of the week with respect to different trader and instrument types.

instruments, we estimate the following system of equations:

$V o l_{t}^{j}=\zeta_{0}+\zeta_{1 i} R V_{t}^{i}+\zeta_{2 i} R V_{t-1}^{i}+\zeta_{3 i} V o l_{t-1}^{j}+v_{2 t}$

$R V_{t}^{i}=\varphi_{0}+\varphi_{1 i} V_{0 l}^{j}+\varphi_{2 i} V_{o l}^{j} l_{t-1}+\varphi_{3 i} R V_{t-1}^{i}+\nu_{1 t}$

In Table 3, the coefficient estimates of contemporaneous terms of our GMM model are documented. The positive contemporaneous relationship between volume and volatility is evident only for domestic customers' spot and forward transactions. As expected, these significant positive relations are observed for local trading session and London and Tokyo trading sessions which overlap the most with the local trading session. For the OTC foreign exchange markets, it is harder to distinguish informed traders from uninformed traders. However, as the literature suggests, institutional investors compared to individuals (Chen \& Daigler, 2008) and foreign investors compared to local investors (Froot \& Ramadorai, 2008; Grinblatt \& Keloharju, 2000) have informational advantage as they have more sophisticated tools to collect private information and act on fundamentals. Thus, the positive contemporaneous relation between volatility and domestic customer spot trade volume confirms the findings of Daigler and Wiley (1999) who argue that volatility is created by uninformed traders. The spot transactions of foreign customers on the other hand, have significant negative contemporaneous relationship with realized volatility, in particular during London and New York trading sessions. The negative relation is because of the fact that the foreigners' trading volume is significantly correlated with their foreign portfolio holdings in Turkish equity and bond markets. Thus, their high trading activity mostly overlaps with resilient periods as flow of funds contribute to foreign exchange liquidity. Therefore, on average we observe a negative relationship between volume and volatility in the special case of foreign customers. Interestingly, in the case of domestic interbank transactions, almost all contemporaneous coefficients are significantly negative. This finding can be attributed to the strategic trading behaviour of domestic banks in the interbank market when the volatility is lower. They also have the informational advantage by knowing both domestic and foreign order flows and having the local market expertise compared to other market participants.

Overall, we can accept MDH only for spot and forward transactions of domestic customers and only for local trading session and the global sessions that have big overlaps with the local trading session.

\subsection{Bivariate dynamic relations}

In this section, to assess the dynamic relationship between volume and volatility, we start with a $\operatorname{VAR}(p)$-DCC $(1,1)-\operatorname{EGARCH}(1,1)$ specification in which the outcome will tell us whether there is bivariate causality and time varying contemporaneous correlation between the two variables. The estimation procedure of these systems of equations has two stages. First, for each transaction volume and realized volatility pair, we select an optimal lag according to Bayesian Information Criteria (BIC) and then estimate a $\operatorname{VAR}(p)$ model as the following:

$V o l_{t}^{j}=\phi_{0}+\sum_{k=1}^{p} \phi_{1 k} \operatorname{Vol}_{T-k}^{j}+\sum_{k=1}^{p} \phi_{2 k} R V_{T-k}^{\mathrm{i}}+u_{t}$

$R V_{t}^{i}=\gamma_{0}+\sum_{k=1}^{p} \gamma_{1 k} R V_{T-k}^{i}+\sum_{k=1}^{p} \gamma_{2 k} \operatorname{Vol}_{T-k}^{j}+v_{t}$

This first stage of estimation not only serves as the mean equation for the conditional variance and dynamic correlation estimations, but also provides a test for bivariate Granger causality. Specifically, as an outcome of these system of equations, two null hypothesis are tested. Rejection of the first null hypothesis of $H_{0}=\gamma_{21}=\gamma_{22}=\ldots \gamma_{2 p}=0$ indicates that trading volume Granger causes realized volatility and the rejection of second hypothesis of $H_{0}=\phi_{21}=\phi_{22}=\ldots=\phi_{2 p}=0$ indicates intraday realized volatility Granger causes trading volume.

In the second stage, we estimate a DCC-EGARCH $(1,1)$ specification. In this model, the error terms in the Eqs. (6) and (7) follow an EGARCH $(1,1)$ process:

$u_{t}=\sqrt{\sigma_{1 t}^{2}} \epsilon_{1 t}$

$\ln \sigma_{1 t}^{2}=\omega_{1}+\beta_{1} \ln \sigma_{1 t-1}^{2}+\gamma_{1} \frac{\epsilon_{1 t-1}}{\sqrt{\sigma_{1 t-1}^{2}}}+\alpha_{1}\left[\frac{\epsilon_{1 t-1}}{\sqrt{\sigma_{1 t-1}^{2}}}-\sqrt{\frac{2}{\pi}}\right]$

$v_{t}=\sqrt{\sigma_{2 t}^{2}} \epsilon_{2 t}$

$\ln \sigma_{2 t}^{2}=\omega_{2}+\beta_{2} \ln \sigma_{2 t-1}^{2}+\gamma_{2} \frac{\epsilon_{2 t-1}}{\sqrt{\sigma_{2 t-1}^{2}}}+\alpha_{2}\left[\frac{\epsilon_{2 t-1}}{\sqrt{\sigma_{2 t-1}^{2}}}-\sqrt{\frac{2}{\pi}}\right]$

and to allow for variation in correlation matrix, we use DCC $(1,1)$ specification developed by (Engle, 2002) which defines time varying variance-covariance matrix as the following: 


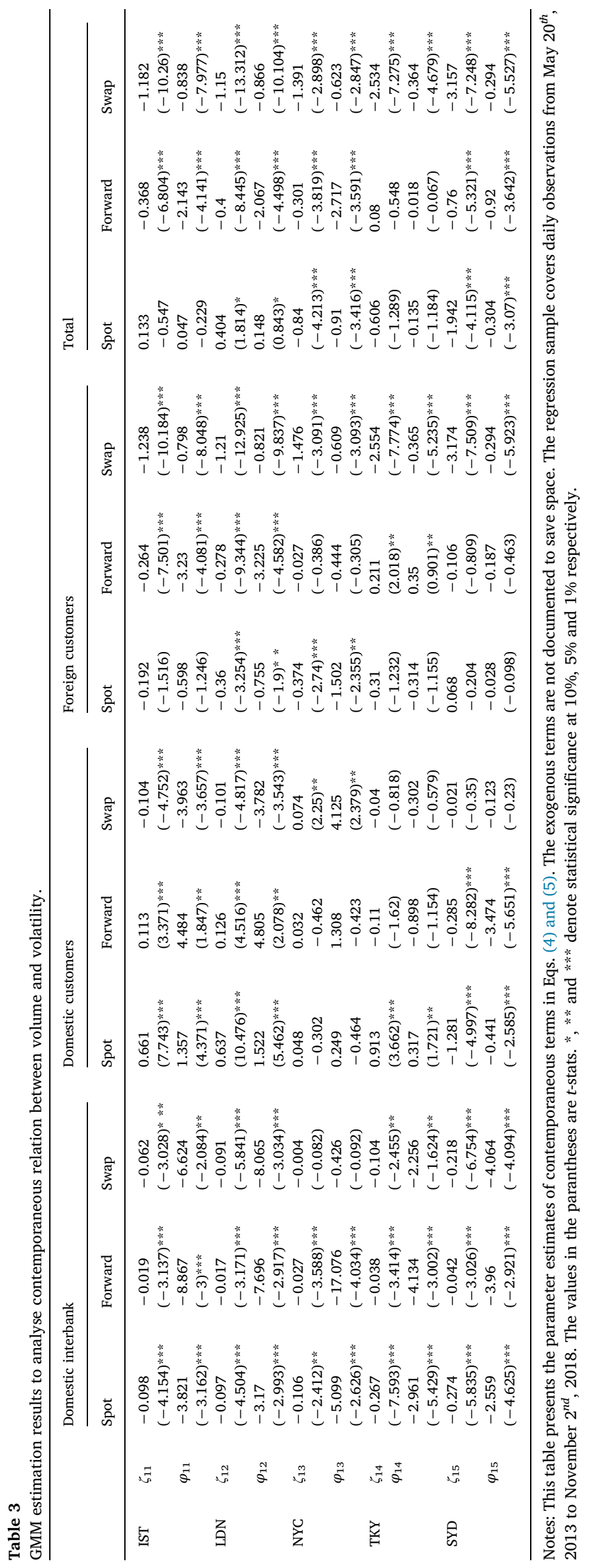




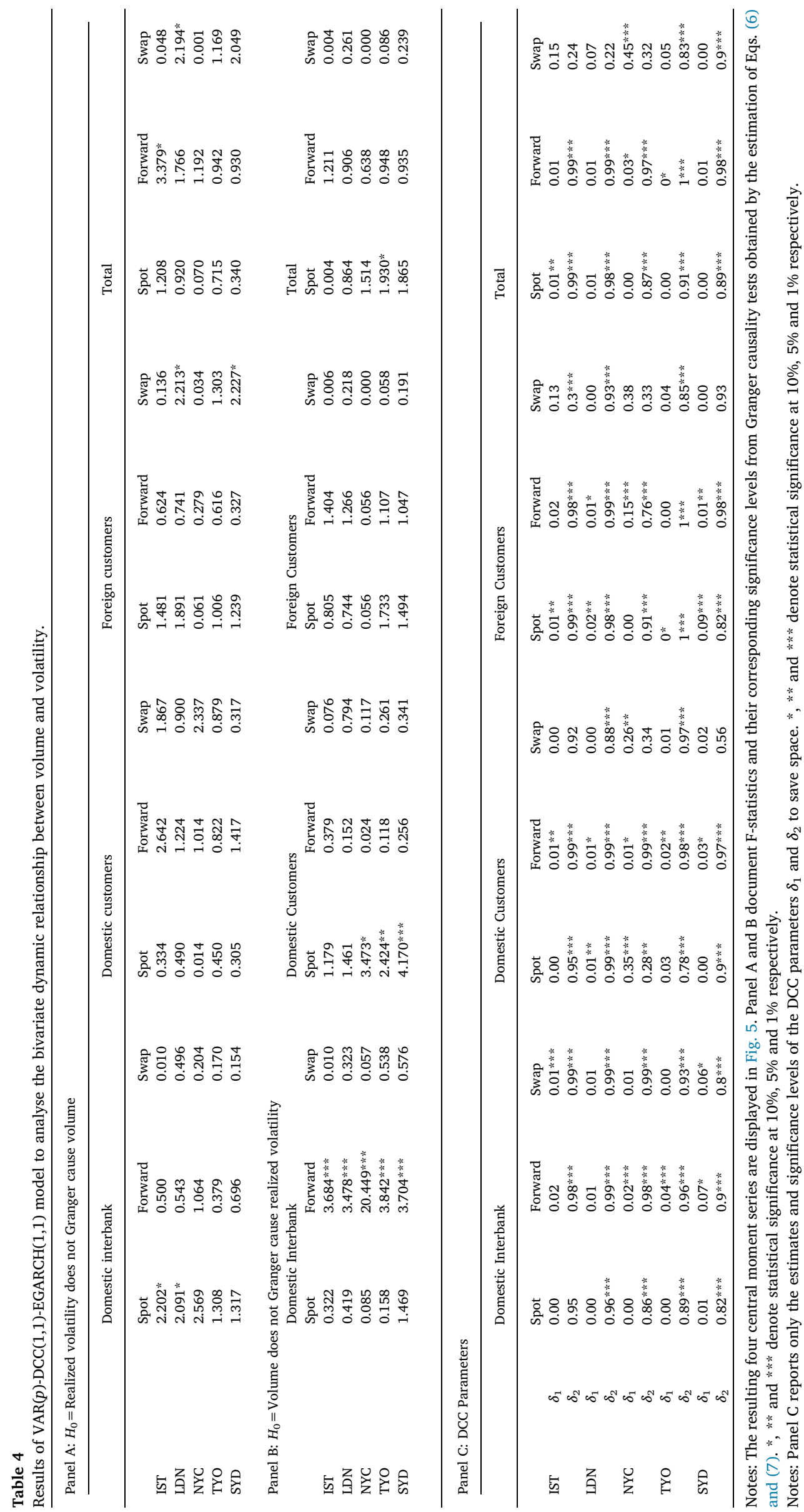



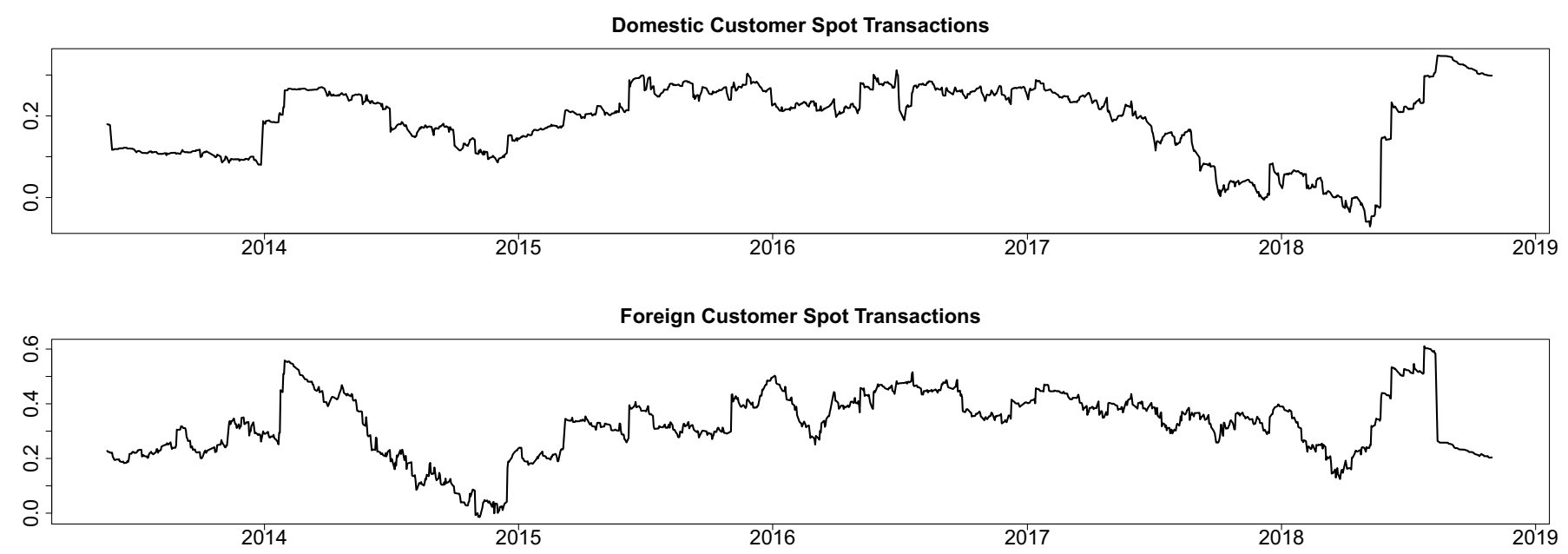

Total Spot Transactions

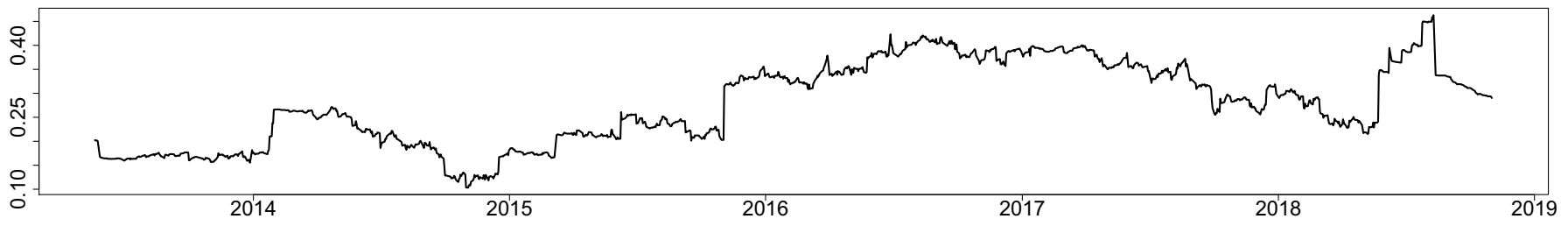

Fig. 4. Dynamic conditional correlations between trading volumes and realized volatility with respect to different trader and transaction types.

$\Sigma_{t}=D_{t}^{1 / 2} R D_{t}^{1 / 2}$

where the time varying correlation matrix is obtained by

$\boldsymbol{R}=\left(\begin{array}{cc}1 & \rho_{12} \\ \rho_{12} & 1\end{array}\right)$

$R_{t}=\operatorname{diag}\left(Q_{t}\right)^{-1 / 2} Q_{t} \operatorname{diag}\left(Q_{t}^{-1 / 2}\right)$

and

$Q_{t}=\left(1-\delta_{1}-\delta_{2}\right) \bar{Q}+\delta_{1}\left(u_{t-1} u_{t-1}^{\prime}\right)+\delta_{2} Q_{t-1}$

in which $\delta_{1}$ and $\delta_{2}$ are DCC $(1,1)$ parameters.

In Panels A and B of Table 4, we document F-statistics and their corresponding significance levels from Granger causality tests obtained by the estimation of Eqs. (6) and (7). The results show that the only Granger causality from realized volatility to volume is observed for total spot transactions. In other words, only with the information of total spot transactions we can improve our forecasts on realized volatility in all trading sessions. Regarding the reverse direction, we observe that forward transactions in the interbank market Granger cause realized volatility in all trading sessions. Moreover, spot transactions of domestic customers Granger cause realized volatility in New York and Sydney trading sessions, possibly because of their trade volume concentration around the early and late hours of the local trading session. Overall, the results are largely insignificant and for the significant cases, the causality between volatility and volume is unidirectional which invalidates SIAH.

We document DCC $(1,1)$ parameters in Panel C of Table 4. The joint significance of the estimated DCC parameters rejects the null hypothesis of a constant correlation. About half of the transaction volume-realized volatility pairs, we reject the null hypothesis of constant correlation which implies that the contemporaneous correlation between the two variables is significantly time-varying.

Among significantly time-varying correlation series, we selectively display major volume-volatility pairs in Fig. 4. One can observe that the correlations increase during severe currency depreciation episodes like first quarter of 2014, and third quarters of 2016 and 2018. In the subsequent section, we relate this variation with the central moments of expectations on the future level of the USDTRY exchange rate.

\subsection{Dispersion of beliefs on contemporaneous dynamic correlations}

A complementary hypothesis for MDH and SIAH that extends our understanding in volume-volatility relationship is the dispersion of belief hypothesis (DBH). The literature contributing to this hypothesis asserts that heterogeneity of expectations on the future value of the investigated asset contributes to positive volume-volatility relationship. For instance, in the work of Shalen (1993), a model of a futures market is derived in which heterogeneity of expectations increases hedging demand and thus contributes to the positive volume and volatility relationship. Similarly, in the models of Harris and Raviv (1993) and Tauchen and Pitts (1983), differences of beliefs on the value of asset being traded increases trading volume and thus price volatility of this asset. Using open interest as a proxy for dispersion of beliefs, Mougoué and Aggarwal (2011) empirically test the impact of dispersion of beliefs on volume and volatility relationship and find that increasing dispersion of beliefs reinforces volume-volatility relationship.

In this section, we extend this literature by testing how belief heterogeneity on future values of USDTRY exchange rate impacts the corresponding volume-volatility relationship. At this stage, we use currency option volatility smiles in order to extract a measure of dispersion of beliefs on a daily basis. Specifically, we derive risk neutral distributions (RNDs) using currency option volatility parameters and then extract their central moments as proxies for expectations. ${ }^{6}$ Use of RNDs' as a proxy for market expectations is common in the literature (Abarca, Rangel, \& Benavides, 2010; Csãvãs, 2010).

There are several methods to derive risk neutral densities from volatility smiles. We use the methodology proposed by Malz (1997) to

\footnotetext{
${ }^{6}$ For calculating a proxy for heterogeneity of expectations on USDTRY exchange rate, we use volatility smile data of USDTRY options obtained from Bloomberg. For each day in our sample, options with 1 month to maturity are used because of their liquidity.
} 

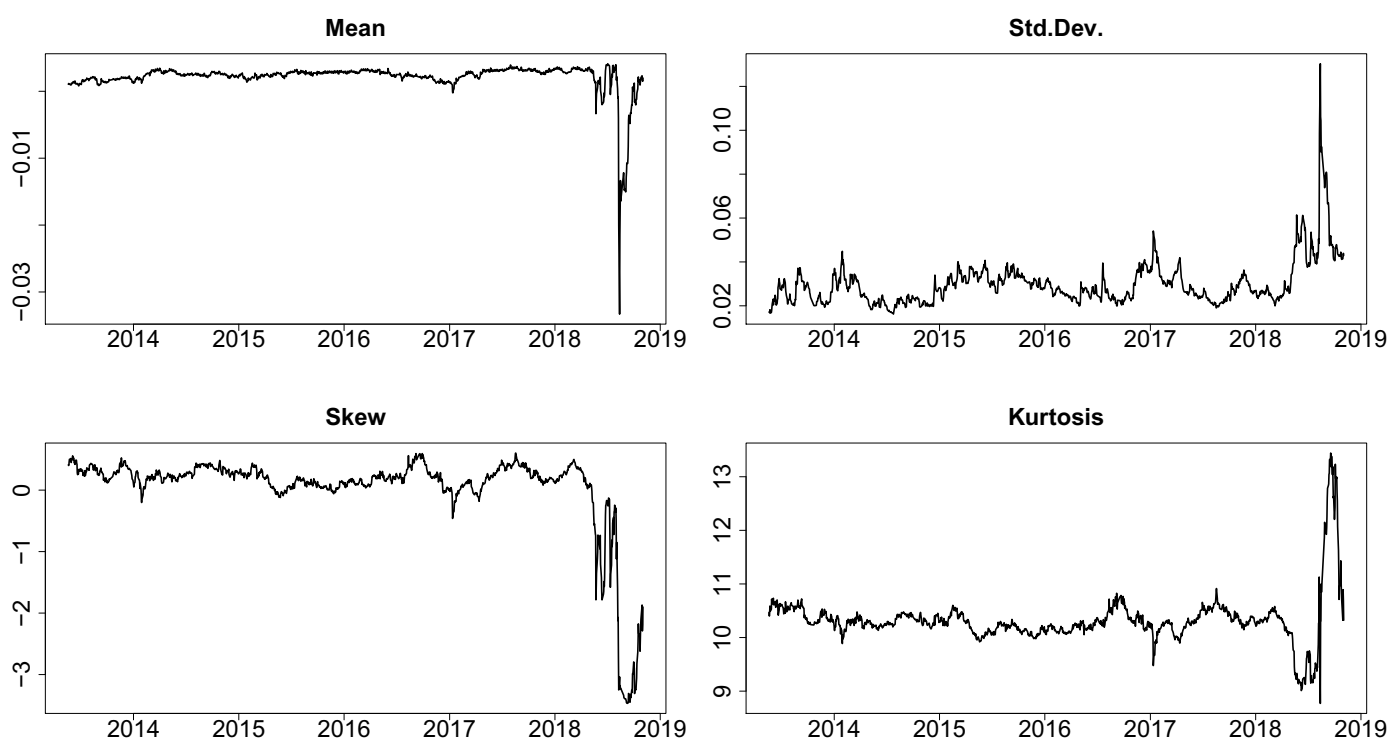

Fig. 5. Central moments derived from risk neutral distributions.

Table 6

Impacts of RND central moments on dynamic correlations between USDTRY volume and volatility.

\begin{tabular}{llll}
\hline & Domestic Spot (LDN) & Foreign Spot (LDN) & Total Spot (IST) \\
\hline$\rho_{t-1}$ & 0.989 & 0.976 & 0.991 \\
& $\left(0.000^{* * *}\right)$ & $\left(0.000^{* * *}\right)$ & $\left(0.000^{* * *}\right)$ \\
$r n d_{\mu}$ & -0.049 & 3.874 & 1.386 \\
& $(0.818)$ & $\left(0.000^{* * *}\right)$ & $\left(0.000^{* * *}\right)$ \\
$r n d_{\sigma}$ & 0.149 & 0.586 & 0.153 \\
& $\left(0.023^{* *}\right)$ & $\left(0.000^{* * *}\right)$ & $\left(0.0036^{* * *}\right)$ \\
$r n d_{\gamma}$ & -0.000 & -0.001 & -0.001 \\
& $(0.740)$ & $(0.718)$ & $\left(0.037^{* *}\right)$ \\
$r n d_{\kappa}$ & -0.002 & 0.004 & 0.000 \\
& $\left(0.010^{* *}\right)$ & $\left(0.016^{* *}\right)$ & $(0.473)$ \\
\hline
\end{tabular}

derive risk neutral densities from currency options. In his setting, author uses the expression for the option-delta and the strike price derived in the work by Breeden and Litzenberger (1978):

$\delta=e^{-r \tau}\left(-\frac{\log \left(\frac{X_{\tau}}{F_{t, \tau}}-\left(\sigma^{2} / 2\right) \tau\right)}{\sigma \sqrt{\tau}}\right)$

and a parametric functional form of the RND is given by:

$\sigma(\delta)=b_{0} a t m_{t}+b_{1} r r_{t}(\delta-0.5)+b_{2} \operatorname{str}_{t}(\delta-0.5)^{2}$

where $a t m_{t}, r r_{t}$ and $s t r_{t}$ represent at the money, 25-delta risk reversal and 25-delta strangle of 1-month currency options respectively. Simultaneous solving of Eqs. (16) and (17) provides RNDs for each trading day. Thus, we obtain risk neutral probabilities $\omega_{i, t}$ for each potential strike price $X_{i, t}$, then we calculate the expected returns as the following:

$r_{i, t}^{e}=\log \left(X_{i, t}\right)-\log \left(S_{t}\right)$

where $S_{t}$ is the spot USDTRY exchange rate on day $t$. Within this framework, central moments are obtained as the following:

- The first central moment, weighted mean gives the location for expectations: $r n d_{\mu}=\sum_{n=1}^{N} \omega_{i} r_{i, t}^{e}$

- As a belief dispersion measure of exchange rate, we obtain the standard deviation of RNDs:

$r n d_{\sigma}=\sqrt{\sum_{n=1}^{N} \omega_{i}\left[r_{i, t}^{e}-\bar{r}_{i, t}^{e}\right]}$

- Skewness of RND's give the tendency of the distribution:

$r n d_{\gamma}=\frac{\sum_{n=1}^{N} \omega_{i}\left[r_{i, t}^{e}-\bar{r}_{i, t}^{e}\right]}{r n d_{\sigma}^{3}}$

- Kurtosis gives probability of extreme returns:

$r n d_{\kappa}=\frac{\sum_{n=1}^{N} \omega_{i}\left[r_{i, t}^{e}-\bar{r}_{i, t}^{e}\right]}{r n d_{\sigma}^{4}}-3$

The resulting four central moment series are displayed in Fig. 5.

The model presented in Eq. (23) helps us to estimate the impact of central moments derived from risk neutral distributions on the dynamic conditional correlations obtained in the previous subsection:

$\rho_{t}=\eta+\rho_{t-1}+r n d_{\mu}+r n d_{\sigma}+r n d_{\gamma}+r n d_{\kappa}+v_{t}$

The regression sample covers daily observations from May 20, 2013 to November 2, 2018. The values in the parentheses are $p$-values. *, ** and $* *$ denote statistical significance at $10 \%, 5 \%$ and $1 \%$ respectively.

Table 6 documents the estimation results of the model in Eq. (23). Accordingly, the dynamic contemporaneous correlation between volume and volatility is significantly and positively affected by the dispersion of beliefs on the future value of the USDTRY exchange rate. Moreover, the level of future exchange rate expectations also has significant positive impact for foreign and total spot transactions.

\section{Conclusion}

The relationship between traded volume and volatility in the FX markets carries a substantial importance for dealers, risk managers, policy makers and regulators. However, the literature on the subject remains shallow due to lack of enriched FX market data. The purpose of this paper is to provide evidence on this relationship for the USDTRY 
exchange rate from an uncharted perspective; that is taking the trader type, transaction type and trading sessions into account at the same time. In order to do that, we create realized volatility series from highfrequency USDTRY exchange rate returns for five major FX trading sessions, namely Istanbul, London, New York, Sydney and Tokyo, and investigate volume-volatility relationship for each session by using a dataset on disaggregated FX transactions volume at both counterparty level (domestic banks, domestic retail and institutional investors, foreign retail and institutional investors) and instrument level (spot, options, forwards, futures, interest rate swaps, currency swaps) collected from all the banks operating in Turkey by the Central Bank of the Republic of Turkey.

Accordingly, through a system Generalized Method of Moments framework, we document a significant positive contemporaneous volume-volatility relationship only for spot transactions of domestic customers and only around local trading hours, a result partially supporting the Mixed Distribution Hypothesis of Clark (1973). With the help of Vector Auto Regression analysis, we further show that there is no evidence for bivariate Granger causality between volume and volatility except for a limited number of cases in Istanbul, New York and Sydney trading hours which rejects the Sequential Information Arrival Hypothesis of Copeland (1976). The dynamic contemporaneous analysis via the DCC methodology shows that the correlation between spot FX volume and realized volatility is positive and significantly time varying. To understand the potential sources that might impact the dynamics of this time varying correlation between volume and volatility, we derive a measure of dispersion of beliefs by using the moments of risk neutral distributions derived from the USDTRY options. The analysis shows that dispersion of beliefs on the level of future USDTRY exchange rate significantly increases correlations between realized volatility and both local and foreign customer spot transaction volumes, eventually supporting the Dispersion of Beliefs Hypothesis of Harris and Raviv (1993) and Shalen (1993).

Overall, our results support the view that the volume-volatility relationship depends on the type of counterparty, traded instrument and the trading session in the FX markets; moreover, it is time varying. The findings of the paper have some important implications for trading and policy objectives. In particular, differential volume-volatility nexus in different counterparties, instruments and trading sessions might help traders enhance their intraday volatility forecasts. Likewise, for regulatory purposes, policy makers need to track market activity for each counterparty and instrument closely, and take into account their differential implications on intraday volatility. For instance, a policy maker should consider the fact that uninformed traders are more likely to increase volatility and in the cases when these investors become active in the market, the policies that aim to mitigate information asymmetries and lower the resulting speculative demand might help currency stabilization and successful liquidity provision. Furthermore, since currency options have been found to provide various components of expectations of the future exchange rate and have implications on volume-volatility nexus, a policy maker might better assess the impact of a restriction or deregulation for a particular instrument on volatility by using the metrics derived from these options.

\section{References}

Abarca, G., Rangel, J., \& Benavides, G. (2010). Exchange rate market expectations and central bank policy: The case of the Mexican peso-US dollar from 2005-2009. Working papers 2010-17. Banco de Mexico.

Admati, A., \& Pfleiderer, P. (1988). A theory of intraday patterns: Volume and price variability. Review of Financial Studies, 1, 3-40.

Balduzzi, P., Kallal, H., \& Longin, F. (1996). Minimal returns and the breakdown of the price-volume relation. Economics Letters, 50, 265-269.

Bauwens, L., Omrane, W. B., \& Giot, P. (2005). News announcements, market activity and volatility in the euro/dollar foreign exchange market. Journal of International Money and Finance, 24, 1108-1125.

Bauwens, L., Rime, D., \& Sucarrat, G. (2006). Exchange rate volatility and the mixture of distribution hypothesis. Empirical Economics, 30, 889-911.

Bessembinder, H., \& Seguin, P. J. (1993). Price volatility, trading volume, and market depth: Evidence from futures markets. Journal of Financial and Quantitative Analysis, 28, 21-39.

BIS (2016). Triennial central Bank survey of foreign exchange and OTC derivatives markets in 2016. Bank for International Settlements1-23.

Bjønnes, G. H., Holden, S., Rime, D., \& Solheim, H. O. A. (2014). Large versus small players: A closer look at the dynamics of speculative attacks. Scandinavian Journal of Economics, 116, 506-538.

Bjønnes, G. H., Rime, D., \& Solheim, H. O. A. (2005a). Liquidity provision in the overnight foreign exchange market. Journal of International Money and Finance, 24, 175-196.

Bjønnes, G. H., Rime, D., \& Solheim, H. O. A. (2005b). Volume and volatility in the FX market: Does it matter who you are? In P. D. Grauwe (Ed.). Exchange rate economics: Where do we stand? (pp. 39-62). MIT Press Ch. 2.

Breeden, D. T., \& Litzenberger, R. H. (1978). Prices of state-contingent claims implicit in option prices. Journal of Business, 51, 621-651.

Breedon, F., \& Ranaldo, A. (2013). Intraday patterns in FX returns and order flow. Journal of Money, Credit and Banking, 45, 953-965.

Chan, C. C., \& Fong, W. M. (2006). Realized volatility and transactions. Journal of Banking and Finance, 30, 2063-2085.

Chan, K., \& Fong, W.-M. (2000). Trade size, order imbalance, and the volatility-volume relation. Journal of Financial Economics, 57, 247-273.

Chang, E. C., Michael Pinegar, J., \& Schachter, B. (1997). Interday variations in volume, variance and participation of large speculators. Journal of Banking and Finance, 21, $797-810$.

Chen, S. S. (2012). Revisiting the empirical linkages between stock returns and trading volume. Journal of Banking and Finance, 36, 1781-1788.

Chen, Z., \& Daigler, R. T. (2008). An examination of the complementary volume-volatility information theories. Journal of Futures Markets, 28, 963-992.

Chordia, T., \& Subrahmanyam, A. (2004). Order imbalance and individual stock returns: Theory and evidence. Journal of Financial Economics, 72, 485-518.

Ciner, C. (2002). Information content of volume: An investigation of Tokyo commodity futures markets. Pacific-Basin Finance Journal, 10, 201-215.

Clark, P. (1973). A subordinated stochastic process model with finite variance for speculative prices. Econometrica, 41, 135-155.

Copeland, T. E. (1976). A model of asset trading under the assumption of sequential information arrival. Journal of Finance, 31, 1149-1168.

Csãvãs, C. (2010). The information content of risk-neutral densities: Tests based on Hungarian currency option-implied densities. European Journal of Finance, 16, 657-676.

Daigler, R. T., \& Wiley, M. K. (1999). The impact of trader type on the futures volatilityvolume relation. Journal of Finance, 54, 2297-2316.

Easley, D., \& O'Hara, M. (1987). Price, trade size, and information in securities markets. Journal of Financial Economics, 19, 69-90.

Engle, R. (2002). Dynamic conditional correlation. Journal of Business \& Economic Statistics, 20, 339-350.

Fischer, A., \& Ranaldo, A. (2008). Does FOMC news increase global FX trading? Working papers 2008-09. Swiss National Bank.

Foster, A. J. (1995). Volume volatility relationships for crude oil futures markets. Journal of Futures Markets, 15, 929-951.

Foster, F. D., \& Viswanathan, S. (1996). Strategic trading when agents forecast the forecasts of others. Journal of Finance, 51, 1437-1478.

Froot, K., \& Ramadorai, T. (2008). Institutional portfolio flows and international investments. Review of Financial Studies, 21, 937-971.

Galati, G., 2001. Trading volumes, volatility and spreads in FX markets: Evidence from emerging market countries. In: Bank for International Settlements, I. (Ed.), Market liquidity: Proceedings of a workshop held at the BIS. Vol. 02. Bank for International Settlements, pp. 197-229.

Gargano, A., Riddiough, S. J., \& Sarno, L. (2008). The value of volume in foreign exchange Working papers 2008-09. Swiss National Bank.

Giot, P., Laurent, S., \& Petitjean, M. (2010). Trading activity, realized volatility and jumps. Journal of Empirical Finance, 17, 168-175.

Gradojevic, N., Erdemlioglu, D., \& Gençay, R. (2017). Informativeness of trade size in foreign exchange markets. Post-printHAL.

Grinblatt, M., \& Keloharju, M. (2000). The investment behavior and performance of various investor types: A study of Finland's unique data set. Journal of Financial Economics, 55, 43-67.

Harris, M., \& Raviv, A. (1993). Differences of opinion make a horse race. Review of Financial Studies, 6, 473-506.

Holthausen, R. W., \& Verrecchia, R. E. (1990). The effect of informedness and consensus on price and volume behaviour. Accounting Review, 65, 191-208.

Koubaa, Y., \& Slim, S. (2019). The relationship between trading activity and stock market volatility: Does the volume threshold matter? Economic Modelling. https://doi.org/10. 1016/j.econmod.2019.01.003 URL.

Kyle, A. (1985). Continuous auctions and insider trading. Econometrica, 53, 1315-1335.

Lakonishok, J., \& Maberly, E. (1990). The weekend effect: Trading patterns of individual and institutional investors. Journal of Finance, 45, 231-243.

Li, J., \& Wu, C. (2006). Daily return volatility, bid-ask spreads and information flow: Analyzing the information content of value. Journal of Business, 79, 2697-2738. 
Luu, J. C., \& Martens, M. (2003). Testing the mixture of distributions hypothesis using realized volatility. Journal of Futures Markets, 23, 661-679.

Malz, A. M. (1997). Option-implied probability distributions and currency excess returns. Staff reports 32. Federal Reserve Bank of New York.

Mougoué, M., \& Aggarwal, R. (2011). Trading volume and exchange rate volatility:

Evidence for the sequential arrival of information hypothesis. Journal of Banking and Finance, 35, 2690-2703.

Osler, C. (2008). Foreign exchange microstructure: A survey. In R. A. Meyers (Ed.). Encyclopedia of complexity and system science (pp. 5404-5543). Springer.
Shalen, C. T. (1993). Volume, volatility, and the dispersion of beliefs. Review of Financial Studies, 6, 405-434.

Tauchen, G., \& Pitts, M. (1983). The price variability-volume relationship on speculative markets. Econometrica, 51, 485-505.

Wagner, N., \& Marsh, T. A. (2005). Surprise volume and heteroskedasticity in equity market returns. Quantitative Finance, 5, 153-168.

Zhang, H. (2018). Intraday patterns in foreign exchange returns and realized volatility. Finance Research Letters, 27, 99-104. 